\title{
Microstrip to Parallel-Strip Nonlinear Transition Balun with Stubs and DGS for UWB Dipole Antenna
}

\author{
S. A. Hamzah ${ }^{\star 1}$, S. Mohd Shah ${ }^{2}$, H. Majid ${ }^{3}$, K. N. Ramli ${ }^{4}$, M. S. Zainal ${ }^{5}$, L. Audah ${ }^{6}$, \\ S. Z. Sapuan ${ }^{7}$, A. Ubin ${ }^{8}$, M. Esa ${ }^{9}$, N. N. Nik Abd Malik ${ }^{10}$ \\ 1,2,3,4,5,6,7,8 Research Centre for Applied Electromagnetic, Centre of Excellent, Universiti Tun Hussein Onn \\ Malaysia, Batu Pahat, Johor, Malaysia \\ ${ }^{9,10}$ Advanced Telecommunication Technology Research Group, Faculty of Electrical Engineering (FKE), \\ Universiti Teknologi Malaysia, Johore Baharu, Johor, Malaysia \\ ${ }^{*}$ Corresponding author, e-mail: shipun@uthm.edu.my
}

\begin{abstract}
Three tapered baluns with nonlinear transition are developed for harmonic suppression in dipole antenna. The first balun consists of an exponential profile with the size of a quarter-wavelength for both the height and width with a wideband characteristic. However, for some applications such as narrowband harmonic suppression antennas and wideband-to-narrowband reconfigurable antennas, the suppression of higher operating band is desired. By employing stubs-filter and a defected ground structure (DGS), two narrowband tapered baluns are produced. They are named as an exponential balun-stub and an exponential balun-DGS, respectively, that operate from 1 to $2 \mathrm{GHz}$. A simulated and measured results that based on the reflection coefficient is found to be better than $-10 \mathrm{~dB}$ from 1 to $2 \mathrm{GHz}$. The employment of the stubs and DGS have enabled these baluns to have the capability to reject the unwanted higher frequency band from 2.0 to $10 \mathrm{GHz}$. Finally, the proposed baluns are employed as a feeding circuit for an ultra wideband (UWB) circular dipole antenna that produces a reasonable outcome.
\end{abstract}

Keywords: Balun-DGS; Balun-stubs; Exponential tapered balun; UWB dipole; Wideband-to-narrowband.

Copyright (C 2017 Universitas Ahmad Dahlan. All rights reserved.

\section{Introduction}

Nonlinear microstrip to parallel-strip transition baluns with broadband and narrowband characteristics are developed to support the fabrication of an ultra wideband (UWB) dipole antenna and harmonic suppression dipole antenna. It is also suitable for an antenna with a planar configuration as well as in a 3-D configuration [1]. In addition, this conversion is very suitable in RF circuits such as phase shifters and filters [2]. A few methods using a range of resistance were incorporated into the study, for instance, a linear tapered balun [3-4].

In addition, there are work on the wideband-narrowband frequency reconfiguration of antennas with integrated switches on the radiating elements that not only introduce complexity but also affect the radiation pattern performance as well as degrade the antenna gain and efficiency. The study on surface current distribution on the transmission line can change the operating frequency of the antenna itself by means of 'on' radiation mode or 'off' radiation mode, respectively. The new exponential tapered balun integrated with stubs and DGS could change the balun characteristic in terms of a wideband-to-narrowband frequency operation capability. The tapered balun in this work is designed based on the work demonstrated in [1] and [3]. The work in [1] presents a linear tapered balun with harmonic suppression capability with attractive features such as wideband, simplicity in its design as well as capable to generate a balanced mode by using open circuit stubs and DGS. Hence, the design offers a new innovation on the tapered balun structure and its function. It also opens a new door to antenna designers to use this concept to design a narrowband balanced antenna by using a tapered balun. The unwanted frequencies in patch antenna (i.e. rectangular or circular) and dipole antenna were effectively removed using an open circuit stubs, EBG circuit, PBG structure, combines PGB and DGS, combines tuning stub and EBG as well, LPF, and introduce the slotted. Other nonlinear tapered baluns such as elliptical and Klopfenstein have been reported in [5-6]. In [5], three different types of baluns (microstrip to broadside parallel strip line) with optimized elliptical produced the best voltage standing wave ratio (VSWR) of less than 1.5 (VSWR $<1.5$ ) from 2 to $18 \mathrm{GHz}$ for 
array antenna applications. On the other hand, Klopfenstein tapered balun using microstrip to broadside parallel-strip line transition produced a similar VSWR from 1.4 to $10.6 \mathrm{GHz}$ [6].

In this study, two designs are proposed namely, nonlinear balun-stub and balun-DGS to suppress higher frequency band from 2.0 to $10 \mathrm{GHz}$. In addition, they are able to eliminate the higher frequency band in the UWB circular dipole antenna. It is aimed for the applications in the cognitive radio (CR) with wideband features such as a personal digital assistant (PDA) in which similarities have been observed in terms of the functionality and performance. On top of that, the proposed baluns can be used to eliminate any unwanted frequency bands. A linear tapered balun with size reduction is published in [3] while its corresponding structure integrated with stubs and DGS has been demonstrated in [1] for harmonic suppression dipole antenna. Other designs of tapered balun that offer simplicity in its structure have been published in [7-9]. The proposed 3-D antenna structure is formed from a circular dipole antenna, stubs-filter, DGS-filter and wideband exponential tapered balun as will be explained in the next section (Section II). The simulation and experimental results are analysed in Section III while the concluding remarks are mentioned in Section IV.

\section{Proposed Design}

The proposed baluns are fabricated on FR- 4 substrate with a dielectric constant of 4.6 and $1.6 \mathrm{~mm}$ of thickness. They are named as Design I, II and III. Figure 1 presents the layout of the baluns in back-to-back configuration. Design I is an exponential tapered balun while Design II and III are an exponential balun-stubs and exponential balun-DGS. Design I is designed at $900 \mathrm{MHz}$ operating frequency with $128 \mathrm{~mm}$ long. Initially, the design is based on a linear configuration with a height and width of $24 \mathrm{~mm}$ and $64 \mathrm{~mm}$ for the bottom configuration. Meanwhile, for the top layer, the height and width of the edges are $0.88 \mathrm{~mm}$ and $2.93 \mathrm{~mm}$, respectively. The calculation of the balun's dimension and its corresponding exponential section are performed using an analytical formula available in [10-12]. The dimension of Design I is 140 $\times 28 \mathrm{~mm}^{2}$. Design II is integrated with five open circuit stubs with dimensions of each stubs to be $13.06 \times 2 \mathrm{~mm}^{2}, 11.23 \times 2 \mathrm{~mm}^{2}, 7.37 \times 2 \mathrm{~mm}^{2}, 6.09 \times 2 \mathrm{~mm}^{2}$ and $4.19 \times 2 \mathrm{~mm}^{2}$. The length is governed by the suppression frequency. In this work, there are five unwanted frequencies that are referred to allow the stubs to eliminate the frequency band of 2 to $10 \mathrm{GHz}$. The location as well as the position and its corresponding width of the stubs are optimized from an extensive parametric study by using CST simulation tool. Design III is the proposed balun integrated with DGS. Similar to Design II, the size of the DGS are exactly the same as the size of the stubs. In this design, five rectangular DGSs are inserted on the tapered balun. They are optimized by means of the position and location by using a parametric study. The corresponding dimensions of the DGS are $13.06 \times 2 \mathrm{~mm}^{2}, 11.23 \times 2 \mathrm{~mm}^{2}, 7.37 \times 2 \mathrm{~mm}^{2}, 6.09 \times 2 \mathrm{~mm}^{2}$ and $4.19 \times 2 \mathrm{~mm}^{2}$. The complete dimensions of these three baluns can be viewed in Table 1.

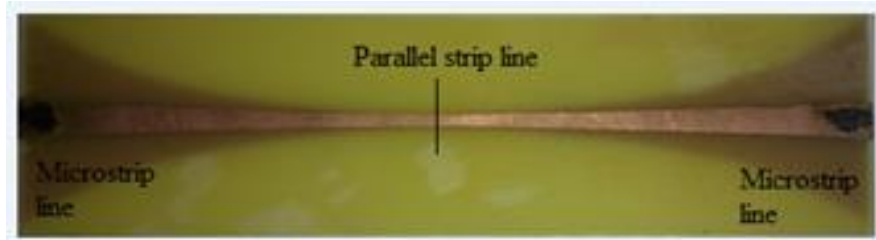

(a)

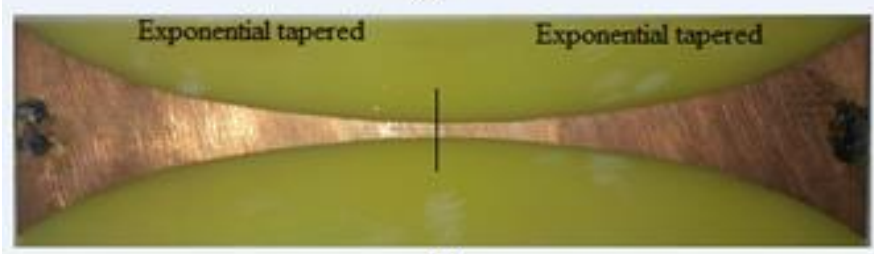

(b)

Figure 1. Back-to-back configuration of Design I (a) Top view and (b) Bottom view 

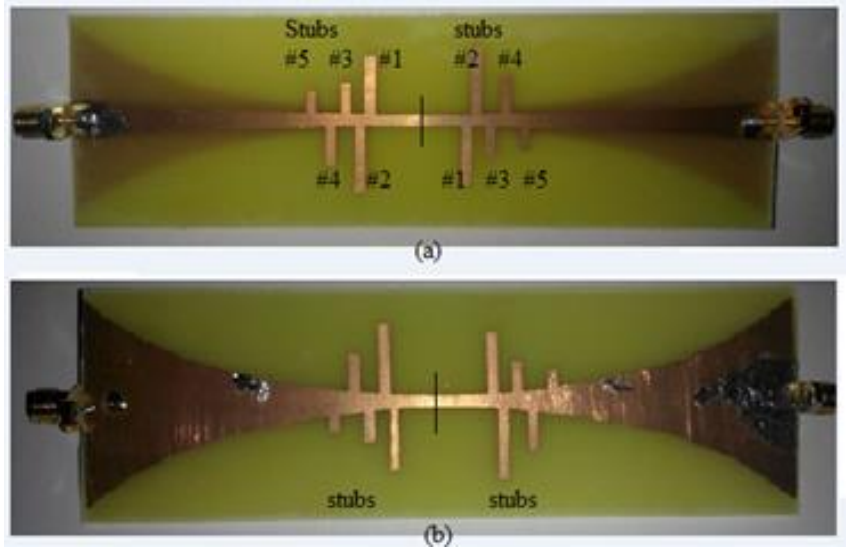

Figure 2. Back-to-back configuration of Design II (a) Top view and (b) Bottom view

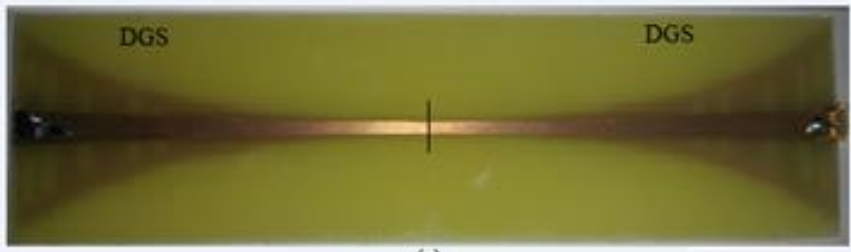

(a)

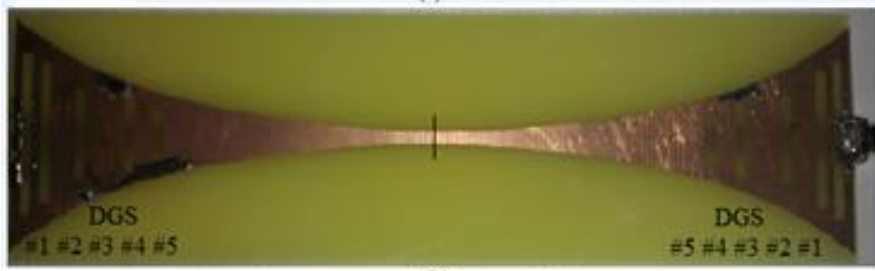

(b)

Figure 3. Back-to-back configuration Design III (a) Top view and (b) Bottom view

Table 1. Proposed Baluns

\begin{tabular}{|c|c|c|c|}
\hline Baluns & Design I & Design II & Design III \\
\hline Width & $64 \mathrm{~mm}$ & $64 \mathrm{~mm}$ & $64 \mathrm{~mm}$ \\
\hline Length & $64 \mathrm{~mm}$ & $64 \mathrm{~mm}$ & $64 \mathrm{~mm}$ \\
\hline & $0.88 \mathrm{~mm}$ & $0.88 \mathrm{~mm}$ & $0.88 \mathrm{~mm}$ \\
\hline Strin line & (top) & (top) & (top) \\
\hline Somp inte & $\begin{array}{l}2.93 \mathrm{~mm} \\
\text { (bottom) }\end{array}$ & $\begin{array}{l}2.93 \mathrm{~mm} \\
\text { (bottom) }\end{array}$ & $\begin{array}{l}2.93 \mathrm{~mm} \\
\text { (bottom) }\end{array}$ \\
\hline \multirow{7}{*}{$\begin{array}{l}\text { Transition } \\
\text { Total size } \\
\text { Stubs/DG } \\
\text { S }\end{array}$} & Non linear & \multirow{3}{*}{$\begin{array}{l}\text { Non linear } \\
3920 \mathrm{~mm}^{2} \\
\text { Stub } 1=13.06 \times 2 \\
\mathrm{~mm}^{2}\end{array}$} & Non linear \\
\hline & $3920 \mathrm{~mm}^{2}$ & & $3920 \mathrm{~mm}^{2}$ \\
\hline & NA & & DGS1 $1=13.06 \times 2 \mathrm{~mm}^{2}$ \\
\hline & NA & \multirow{4}{*}{$\begin{array}{l}\text { Stub } 2=11.23 \times 2 \\
\mathrm{~mm}^{2} \\
\text { Stub } 3=7.37 \times 2 \mathrm{~mm}^{2} \\
\text { Stub } 4=6.09 \times 2 \mathrm{~mm}^{2} \\
\text { Stub } 5=4.19 \times 2 \mathrm{~mm}^{2}\end{array}$} & DGS2 $=11.23 \times 2 \mathrm{~mm}^{2}$ \\
\hline & NA & & DGS3 $=7.37 \times 2 \mathrm{~mm}^{2}$ \\
\hline & NA & & DGS4 $=6.09 \times 2 \mathrm{~mm}^{2}$ \\
\hline & NA & & DGS5 $=4.19 \times 2 \mathrm{~mm}^{2}$ \\
\hline
\end{tabular}

The configuration of the proposed antenna is illustrated in Figure, 4 to 6 . The microwave board used is a low cost substrate, FR-4 board as mentioned before. The radiating element is $1.5 \mathrm{~mm}$ thick with $132 \mathrm{~mm} \times 20 \mathrm{~mm}$ of height and length. The baluns in Figure 1 and its corresponding modifications as shown in Figure 2, 3 are used as a feeding circuit to an UWB dipole antenna as shown in Figure 4, 6. They are named as Antenna I, Antenna II and Antenna III, respectively. The complete dimensions of the antennas are listed in Table 2. 


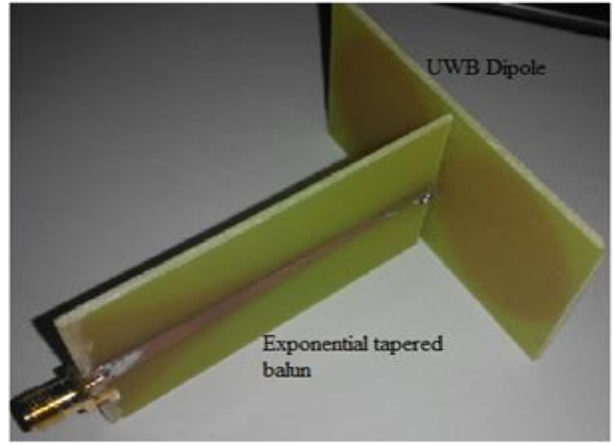

Figure 4. Antenna I

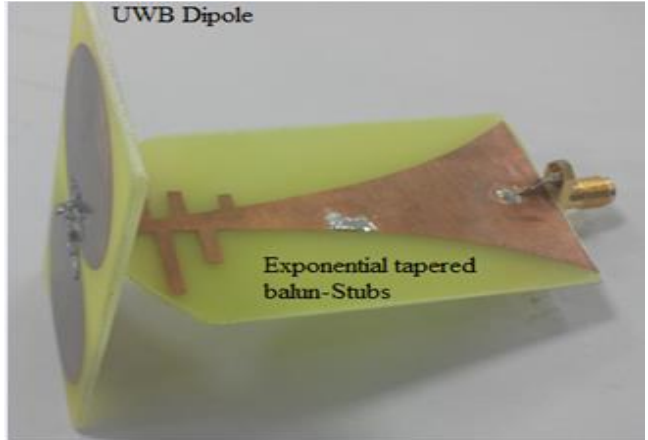

Figure 5. Antenna II

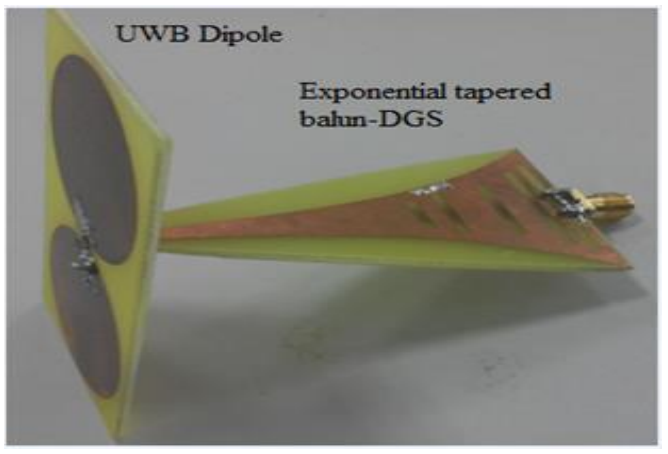

Figure 6. Antenna III

Table 2. Proposed 3-D Circular Dipole Antenna with Integrated Balun

\begin{tabular}{llcl}
\hline Parameter & Antenna I & Antenna II & Antenna III \\
\hline Radius & $20 \mathrm{~mm}$ & $20 \mathrm{~mm}$ & $20 \mathrm{~mm}$ \\
Bandwitdh & Wideband & Narrowband & Narrowband \\
$\begin{array}{l}\text { Feeding } \\
\text { circuit }\end{array}$ & Design I & Design II & Design III \\
Total size & $\begin{array}{l}42 \times 64 \times 140 \mathrm{~m} \\
\mathrm{~m}^{3}\end{array}$ & $42 \times 64 \times 140 \mathrm{~mm}^{3}$ & $42 \times 64 \times 140 \mathrm{~mm}^{3}$ \\
\hline
\end{tabular}

\section{Results and Analysis}

In this section, the results of the proposed baluns (refer to Figures 1 to 3 ) and the corresponding integration of the baluns with a 3-D UWB dipole antenna (refer to Figures 4 to 6 ) are discussed. The analysis is based on the reflection coefficient graphs simulated in CST MWS software and measured by using a Vector Network Analyser (VNA).

\subsection{Proposed Balun}

Figure 7 presents the simulated and measured reflection coefficient of the exponential tapered balun (refer to Figure 1). From the figure, it can be seen that the balun operates at the $10 \mathrm{~dB}$ bandwidth with $\mathrm{S}_{11}$ less than $-10 \mathrm{~dB}$ from 1 to $10 \mathrm{GHz}$. A good agreement can also be seen between the simulation and measurement results.

The simulated and measured reflection coefficient of the exponential balun-stubs (refer to Figure 2) from 1 to $10 \mathrm{GHz}$ are presented in Figure 8. The proposed balun has the $\mathrm{S}_{11}$ better than $-10 \mathrm{~dB}$ from 1.0 to $1.4 \mathrm{GHz}$. The measured reflection coefficient of approximately $-3 \mathrm{~dB}$ from 2.0 to $10 \mathrm{GHz}$ shows that the balun is mismatched and thus, the stubs effectively work as an internal filter. In conclusion, the integration of five stubs to the balun has changed the operating frequency band from a wideband to narrowband. 


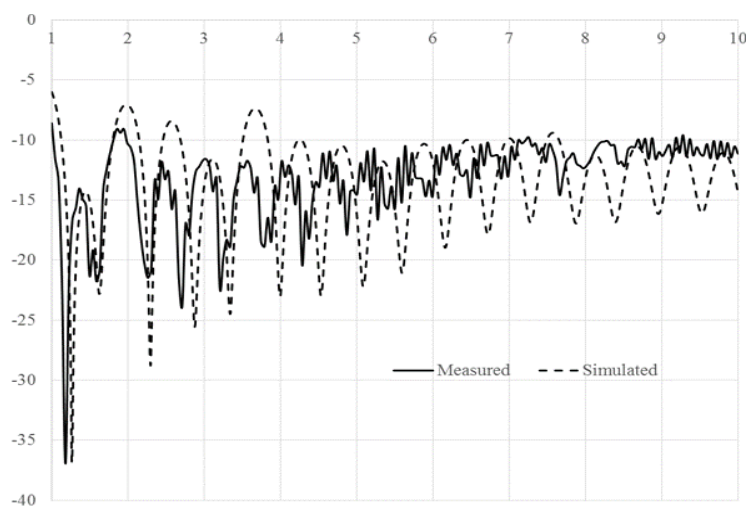

Figure 7. Simulated and measured reflection coefficient of Design I balun

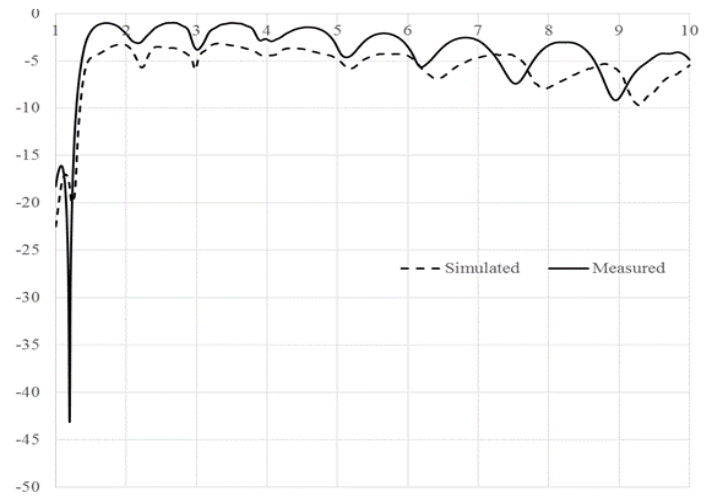

Figure 8. Simulated and measured reflection coefficient of Design II balun

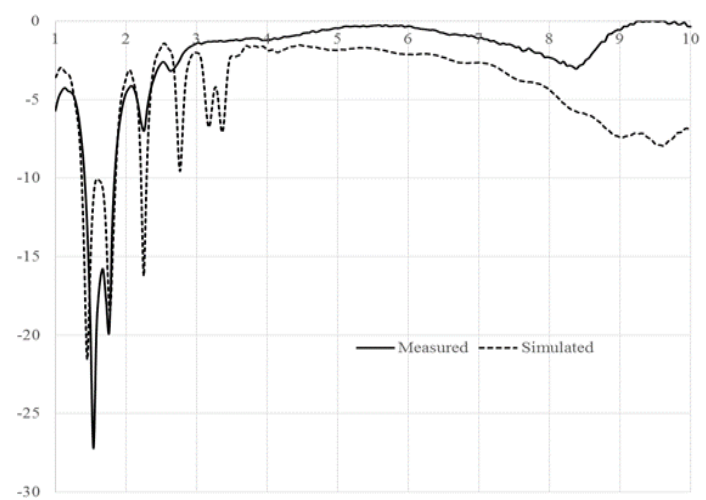

Figure 9. Simulated and measured reflection coefficient of Design III balun

On the other hand, the performance of the exponential balun-DGS (refer to Figure 3) that is capable to suppress the higher frequency band is presented in Figure 9. A good agreement is observed between the simulation and measurement results. The measured reflection coefficient of the balun is better than $-10 \mathrm{~dB}$ from 1.4 to $2.0 \mathrm{GHz}$ that varies from -10 $\mathrm{dB}$ minimum to $-27 \mathrm{~dB}$ maximum. When the frequency exceeds $2.0 \mathrm{GHz}$, the measured result varies from -6.0 to $-0.5 \mathrm{~dB}$ which indicates that the balun is well mismatched. It can be inferred that the integration of the DGS has changed the broadband characteristic to narrowband.

\subsection{Proposed Antenna with Integrated Balun}

Figure 10 shows the simulated and measured reflection coefficient of the circular dipole antenna with Design I balun (refer to Figure 4). It can be clearly seen that the results obtained have a good agreement between each other. The operating frequency of the antenna is wideband that operates within the 1.80 to $10 \mathrm{GHz}$ frequency range. The corresponding reflection coefficient are from $-30 \mathrm{~dB}$ maximum to $-10 \mathrm{~dB}$ minimum.

In Figure 11, the graph of simulated and measured reflection coefficient of the circular dipole antenna with Design II balun (refer to Figure 5) is presented. The antenna works at a narrow frequency band centered at $1.9 \mathrm{GHz}$ with $\mathrm{S} 11$ of $-10 \mathrm{~dB}$. The balun-stubs has successfully suppressed the frequency within the range of 2.0 to $10 \mathrm{GHz}$ and hence, operating at narrowband frequency. These unwanted band has reflection coefficient of $-7 \mathrm{~dB}$ maximum to $-4 \mathrm{~dB}$ minimum. 


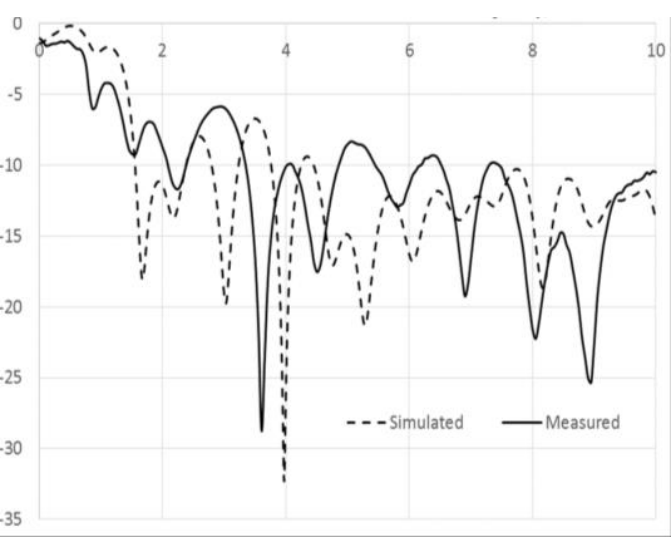

Figure 10. Simulated and measured reflection coefficient of Antenna I

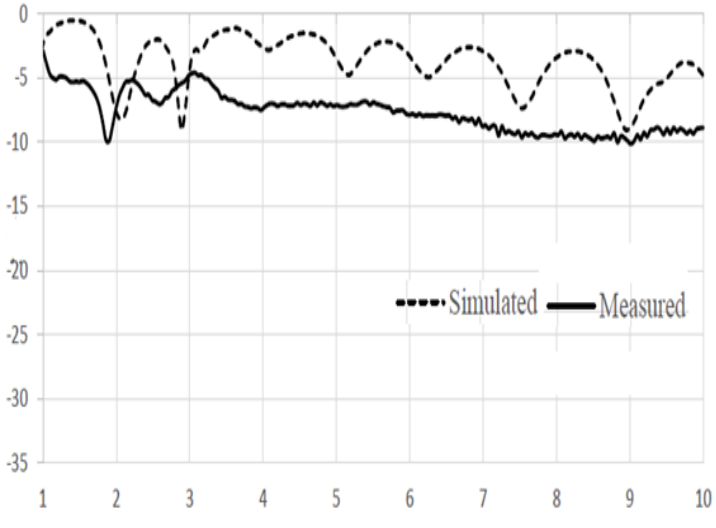

Figure 11: Simulated and measured reflection coefficient of Antenna II

Figure 12 is the simulated and measured reflection coefficient of the circular dipole antenna with Design III balun (refer to Figure 6). The antenna works at a narrow band frequency of $1.8 \mathrm{GHz}$ with a reflection coefficient of $-13 \mathrm{~dB}$. The feeding circuit with balun-DGS has successfully suppressed the frequency band within the frequency range of 2.0 to $10 \mathrm{GHz}$ which makes the antenna operates at narrowband frequency. The corresponding $\mathrm{S} 11$ is $-5 \mathrm{~dB}$ maximum to $-1 \mathrm{~dB}$ minimum, respectively.

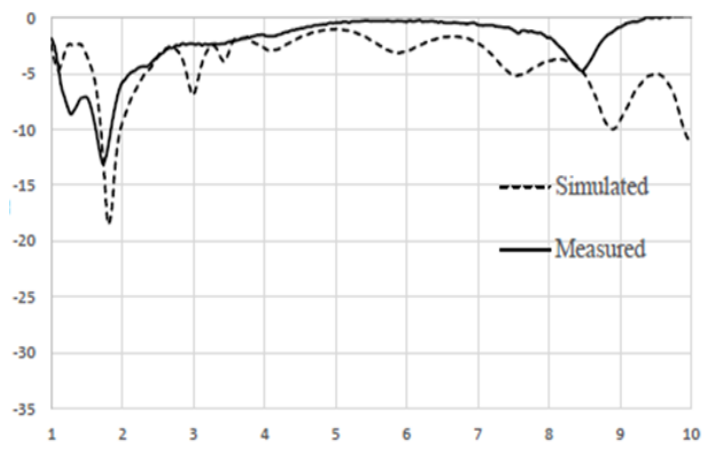

Figure 12. Simulated and measured reflection coefficient of Antenna III

\section{Conclusion}

A conclusion to review the main points of the paper, do not replicate the abstract as the conclusion. A conclusion might elaborate on the importance of the work or suggest applications and extensions. In this work, two nonlinear optimized tapered baluns that use microstrip to parallel-strip conversion with five integrated open circuit stubs and five rectangular DGS have been proposed. The employment of these baluns have greatly contributed to the matched impedance between the microstrip line and parallel-strip line. These baluns can be used in RF devices with a particular emphasize on antennas due its wideband characteristic, simplicity in its design and ease of conversion to narrowband frequency. By employing these baluns, an UWB dipole antenna with integrated stubs and DGS are proposed as to suppress the harmonics. The UWB antennas can also be referred to as harmonic-suppression 3D-dipole antennas. The measurements of reflection coefficient is found to be better than $-10 \mathrm{~dB}$ from 0 to $2.0 \mathrm{GHz}$ of frequency band while mismatched are observed at higher frequency band from 2.0 to $10 \mathrm{GHz}$. The results show that a circular dipole antenna has the capability to suppress a frequency range of unwanted harmonics reasonably. 


\section{References}

[1] Hamzah SA, Esa M, Ramli KN, Dahlan SH, Mohd Jenu MZ, Sapuan SZ. Microstrip-to-Parallel Strip Transition Balun Integrated with Stubs and DGS for 3-D Harmonic Suppressed Dipole Antenna. Asia Research Publishing Network (ARPN) Journal. 2015; 19(10): 9027-9030.

[2] Chiu L, Xue Q, Chan $\mathrm{CH}$. Performance enhancement of microwave circuit using parallel strip line. IEEE Journal and Magazine. 2010; 29(5): 16-21.

[3] Vinayagamoothy K, Coetzee J, Jayalath D. Microstrip to Parallel Strip Balun as Spiral Antenna Feed. Proceedings of VTC2012. 2012: 1-5.

[4] Hamzah SA, Esa M, Nik Abd Malik NN, Ismail MKH. Broadband Microstrip-to-Parallel Strip Transition Balun with Reduced Size. Proceedings of APMC2012. 2012: 172-174.

[5] Rizvi SAP, Khan RAA. Klopfenstein Tapered 2-18 GHz Microstrip Balun. IEEE Proceedings. 2012: $1-4$.

[6] Kumar T, Harish AR. Wideband Directive Dipole Antenna with Integrated Balun. Proceedings of APSURSI. 2012: 1-2.

[7] Lee H. CPW-fed to CPS Dipole Antenna of Microstrip Tapered Balun with Triangular Loop Director. Journal of Electral EngineeringTechnology. 2014; A(b): 742-745.

[8] Bah AO, Qin PY, Guo YJ. An Extremely Wideband Tapered Balun for Application in Tightly Coupled Arrays. Proceedings of APWC 2016. 2016: 162-165.

[9] Li J, Li L, Zhang A, Liu J, Liu QH. Wideband Two Bowtie Dipole Array Antenna Integrated with a Tapered Balun. Proceedings of ISAPE 2016. 2016: 16-18.

[10] Pozar DM. Microwave Engineering. $3^{\text {rd }}$ edition. John Wiley \& Sons. 2005.

[11] Paul CR. Introduction to Electromagnetic Compatibility. $2^{\text {nd }}$ edition. New York: John Wiley \& Sons. 2006.

[12] Vahdani M. Low profile ultra wideband and dual polarized antennas and feeding systems. Unpublished PhD dissertation. France: Telekom Paris Tech; 2008. 